\title{
The Importance of Endogenous Nutrition of Chicks from Divergent Strains for Growing Tested by Deutectomy
}

\section{Author(s)}

Gonzales $\mathrm{E}^{1}$

Leandro NSM ${ }^{2}$

Dalke $\mathrm{F}^{3}$

Brito $A B^{4}$

Cruz $C P^{5}$

Volunteer Professor, Livre Docente (Habilitation Degree), Faculdade de Medicina Veterinária e Zootecnia, UNESP, Botucatu, SP, Brazil.

2 Associate Professor, Escola de Veterinária, UFG, Goiânia, GO, Brazil.

3 Associate Professor, DZ, SCA. UFPR, Curitiba, PR, Brazil

4 DVM, Ph. D., Poli-nutre Alimentos Ltda, Osasco, SP, Brazil

5 DVM, M.Sc., Perdigão Agropecuária S/A, Rio Verde, GO, Brazil.

\section{Mail Address}

Elisabeth Gonzales

Rua Justino Miranda Camargo, 1386

18.610-130. Botucatu, SP, Brazil

E-mail: elisa.gonzales@uol.com.br

\section{Keywords}

Body weight, chick, deutectomy, strain, yolk sac.

\section{Acknowledgments}

To CNPq and FAPESP for financial support.

\section{ABSTRACT}

Effects of yolk sac removal (deutectomy) upon performance of chicks from three divergent strains were tested to evaluate the importance of endogenous nutrition on the post-hatch phase. Chicks from three different strains (Hy-Line W98, Cobb 500, and JA57) were submitted to a surgery procedure after hatching. Half of them had the residual yolk removed, and the other constituted a sham-deutectomized group. After operation, chicks were designated to a $3 \times 2$ factorial design (3 strains $\times 2$ presence/absence of yolk sac), in a total of six experimental groups and ten replications of two to four birds. During 14 experimental days all birds were fed ad libitum a $21 \%$ CP and $3050 \mathrm{kcal} / \mathrm{kg}$ EM mash diet. Data were analyzed by ANOVA, and Tukey's test $(p<0.05)$. Relative yolk sac weights were similar among chicks from different breeders, averaging $11.7 \%$ to $13.5 \%$. Comparing to sham-operated, deuctetomized chicks had lower weight gain at 7 and $14 d$, indicating that endogenous nutrition, via yolk sac, is very important to galliform birds whatever their strain. Hy-line deutectomized chicks gained $40 \%$ less body weight at the $7^{\text {th }}$ day as compared to their sham counterparts. Analysis of the same criterion to Cobb and JA57 groups revealed a decrease of $16.1 \%$ and $10.8 \%$, respectively, on weight gain efficiency. At the 14th rearing day, Hy-Line chicks had the lowest weight gain, followed by JA57s' and Cobbs'. The results suggested that chicks selected for fast growth are less dependent on endogenous nutrition, responding better when exogenous nutrition is associated to yolk assimilation.

\section{INTRODUCTION}

Some authors support the theory that growth of neonatal birds is highly dependent on endogenous nutrition through residual egg yolk. However, delayed early feeding of newly hatched chicks depresses performance of 42-d-old broilers (Gonzales et al., 2000, 2003). This fact indicates that the supplementation of nutrients via residual yolk seems not sufficient to support the extremely high growth rate of broiler chicks in their initial post-hatch period.

According to Nitsan et al. (1991), the size of yolk sac from birds selected for high growth rate (broiler chick) is smaller than those having slow development, as White Leghorn birds. Thus, the use of residual yolk and the need of exogenous nutrition (feed) of neonatal chicks from divergent background for growing could be different and related to at least two factors, the genetic constitution of the bird, and the duration of feed deprivation immediately after hatching.

The effect of removing the yolk sac (deutectomy) upon the performance of chicks was tested in order to evaluate the importance of the endogenous (residual yolk) nutrition to chicks from breeders of divergent background for growing. 


\section{Gonzales E, Leandro NSM, Dalke F, Brito AB, Cruz CP}

\section{MATERIAL AND METHODS}

Chicks used in this trial were obtained from breeder eggs of three strains, one from a broiler line selected for high growth rate and excellent feed conversion (Cobb 500), the second also from a broiler strain, but not selected to fast growth (JA57 - naked neck), and the third from white egg-layer strain (Hy-Line W98). Eggs from breeders in the middle of their productive period were selected to represent the average weight $5 \%$ at a given stage of egg production. Breeder ages were 48,43 , and 50 weeks, and the mean egg weights were 62, 60.5, and $65 \mathrm{~g}$ for Hy-Line, Cobb and JA57 breeders, respectively.

The chicks were subjected to a surgical procedure immediately after hatching, defined as the time when birds completely left the shell. Half of them had the residual yolk removed. The other half constituted a sham deutectomized group for whom a simple incision of the skin was done.

The following surgical procedure was adopted according to modified method reported by Chambele et al. (1992): 1) Mark; 2) Weigh; 3) Removal of downs next to navel area; 4) Disinfection by swabbing the area with tincture of iodine; 5) Infusion of $0.3 \mathrm{~mL}$ of Pearson anesthetic, 6) Incision of the skin on the right side of the navel hole; 7) Opening of abdominal cavity and exposure of the yolk sac; 8) Cutting of the yolk sac stalk at the point of attachment to Meckel's diverticulum; 9) Excision of yolk sac (deutectomy), when appropriate; 10) Closing of surgical incision with catgut strap 3-0; 11) $0.5 \mathrm{~mL}$ IM injection of PentVet Plus; 12) Resting of the chicks for at least 2 hours in heated environment using a 60W lamp.

After operation, the chicks were designated to a 3 $\times 2$ factorial design (3 strains $\times 2$ presence/absence of yolk sac), in a total of 6 experimental groups and 10 replications of 2 to 4 birds each. The birds were distributed in three batteries, each with five floors divided in two boxes. Each floor of the batteries was considered one experimental block. When necessary, the thermoneutral conditions of chicks during the rearing period were achieved by the use of infrared lamps placed in front of the batteries. During 14 days of rearing, all birds were fed ad libitum a $21 \%$ CP and $3050 \mathrm{kcal} / \mathrm{kg}$ EM mash diet. Because spillage occurred, feed intake was not recorded.

Data were analyzed by ANOVA for a $3 \times 2$ factorial arrangement using the General Linear Model of SAEG (1999) software. Significant differences among means were separated by Tukey's test. $(p<0.05)$.

\section{RESULTS AND DISCUSSION}

Similar to what occurred in a previous experiment (Gonzales et al.., submitted), the relative weight of yolk sac from chicks of different genetic backgrounds were not different (Table 1). However, the values here obtained were lower, ranging from 11.7 to $13.5 \%$ of the live weight. The period between hatching and measurement of the yolk sac was long due to the deutectomy procedure, demanding a long time to collect the weight of the yolk sac. Thus, the possibility that some residual yolk was consumed during the waiting time exists as formerly observed by Noy and Sklan (2001). However, Chamblee et al. (1992) reported that during $12 \mathrm{~h}$ after hatching no significant use of residual yolk by broiler chicks was verified. So, origin and age differences of neonatal birds should be considered when analyzing yolk residue measurements.

The statistical evaluation of body weight and weight gain at 7th and 14th experimental days showed a significant effect $(p<0.05)$ of strain and deutectomy (Table 2). However, no interaction ( $p>0.05$ ) between the two factors was observed (Table 2). As compared to sham-operated chicks, deutectomized birds had significantly lower body weight and weight gain at 7 and 14 days of age, indicating that endogenous nutrition was very important for the birds whatever their strain origin. However, it is necessary to mention that the surgical procedure was in itself a stress factor that influenced feed and water consumption for at least 24 hours after the deutectomy procedure. Independently of surgical procedure Cobb chicks performed better than JA57 and Hy-Line, as expected.

The weight gain of Hy-Line deutectomized chicks was $40 \%$ lower than their sham-operated counterparts (sham-operated, non-deutectomized Hy-Line chicks). On the other hand, the analysis of the same criterion (detutectomized against sham-operated) in Cobb and JA57 groups revealed $16.1 \%$ and $10.8 \%$ lower weight gain, respectively (Table 3 ). At 14 days of rearing, HyLine deutectomized chicks presented $-13.6 \%$ weight gain as compared to non-deutectomized counterparts. For JA57 and Cobb chicks, differences in weight gain between detectomized and non-deutectomized were $-12.1 \%$ and $-9.7 \%$, respectively.

Thaxton (1984) demonstrated that broiler chicks were able to compensate deutectomy four weeks later. However, Gonzales et al.(2000, 2003) observed growth depression in broiler chicks fasted for $24 \mathrm{~h}$ in neonatal period, similar to the effect of deutectomy. 
The initial growth depression due to feed deprivation was not compensated 42 days later (Gonzales et al., 2003), indicating that good initial nutrition, both endogenous (residual yolk) and exogenous (diet), is essential for the expression of the growth according to the genetic background of the bird.

\begin{tabular}{|c|c|c|c|}
\hline \multirow[b]{2}{*}{ Strain } & \multicolumn{3}{|c|}{ Yolk sac weight, } \\
\hline & Body weight, g & $\mathrm{g}$ & $\% 1$ \\
\hline Hy-Line W98 & $40.0 c$ & $4.67 b$ & 11.71 \\
\hline Cobb 500 & $46.6 b$ & $5.98 a$ & 12.75 \\
\hline JA57 & $49.2 a$ & $6.73 a$ & 13.53 \\
\hline
\end{tabular}

$a, b$ - Values sharing no common superscripts in the same column are statistically different (Tukey's test, $p<0.05$ ). 1 - Relative to body weight.

Table 2 - Body weight and weight gain on 7th and 14th experimental days of chicks from different strains subjected or not to deutectomization.

\begin{tabular}{|c|c|c|c|c|}
\hline \multirow[b]{2}{*}{ Parameters } & \multicolumn{2}{|c|}{7 days } & \multicolumn{2}{|c|}{14 days } \\
\hline & $\begin{array}{c}\text { Body } \\
\text { weight, } g\end{array}$ & $\begin{array}{l}\text { Weight } \\
\text { gain, g }\end{array}$ & $\begin{array}{c}\text { Body } \\
\text { weight, } g\end{array}$ & $\begin{array}{l}\text { Weight } \\
\text { gain, g }\end{array}$ \\
\hline \multicolumn{5}{|l|}{ Strains } \\
\hline Hy-Line W98 & $55.4 \mathrm{c}$ & $19.3 c$ & $101.9 c$ & $65.8 \mathrm{c}$ \\
\hline Cobb 500 & $125.9 a$ & $83.6 a$ & $309.0 a$ & $266.8 a$ \\
\hline JA57 & $94.8 \mathrm{~b}$ & $51.4 b$ & $207.0 b$ & $163.8 b$ \\
\hline \multicolumn{5}{|l|}{ Deutectomy } \\
\hline Yes & $83.9 x$ & $46.4 x$ & $193.4 x$ & $155.9 x$ \\
\hline $\begin{array}{l}\text { No } \\
\text { Effects }\end{array}$ & $100.0 y$ & $56.5 y$ & $218.6 y$ & $175.1 y$ \\
\hline Strain (S) & * & * & * & * \\
\hline Deutectomy (D) & * & * & * & * \\
\hline$S \times D$ & NS & NS & NS & NS \\
\hline
\end{tabular}

* - Significant $(p<0,05)$. NS Not significant $(p>0,05)$. $a, b, c$, Values sharing no common superscript in the same column are statistically different by Tukey's test at $p<0.05$ (strain effect). $x, y$ - Values sharing no common superscript in the same column are statistically difference by F's test at $p<0.05$ ) (deutectomy effect).

Table 3 - Relative difference (Dif, \%) on weight gain at 7th and 14th experimental days among deutectomized (D) and nondeutectomized (ND) chicks from different strains.

\begin{tabular}{|c|c|c|c|c|c|c|}
\hline \multirow[b]{3}{*}{ Strains } & \multicolumn{6}{|c|}{ Weight gain, g } \\
\hline & \multicolumn{3}{|c|}{7 days } & \multicolumn{3}{|c|}{14 days } \\
\hline & D & ND & Dif, \% & D & ND & Dif, \% \\
\hline Hy-Line W98 & $14,4 a$ & $24,1 b$ & $-40.2 \%$ & $60,5 a$ & $70,5 b$ & $-13.6 \%$ \\
\hline Cobb 500 & $76,3 a$ & $90,9 b$ & $-16.1 \%$ & $253,1 a$ & $280,4 b$ & $-9.7 \%$ \\
\hline JA57 & $48,5 a$ & $54,4 b$ & $-10.8 \%$ & 154,0 & $175,2 b$ & $-12.1 \%$ \\
\hline
\end{tabular}

$a, b, c$ - Values sharing no common superscript in the same column are statistically different by Tukey's test at $p<0.05$.

The mortality indexes were relatively low (only 2 to 3 birds per experimental units) and were not statistically different among treatment groups (Table 4). However, all deutectomized groups displayed some mortality, indicating that the method affected the birds, mainly the Hy-Line ones. Placing the feeder and the drinker inside the box as a management procedure to facilitate the access of the birds, encouraging feed and water consumption, was very important to improve the liability and the performance depressed by surgical process.

\begin{tabular}{|c|c|c|c|c|c|}
\hline \multirow[b]{2}{*}{ Strain } & \multicolumn{3}{|c|}{7 days } & \multicolumn{2}{|c|}{14 days } \\
\hline & Deutectomy & N/total & $\%$ & N/total & $\%$ \\
\hline \multirow[t]{2}{*}{ Hy-Line W98 } & Yes & $3 / 20$ & 15.00 & $3 / 20$ & 15.00 \\
\hline & No & $2 / 20$ & 10.00 & $3 / 20$ & 15.00 \\
\hline \multirow[t]{2}{*}{ Cobb 500} & Yes & $2 / 35$ & 5.71 & $2 / 35$ & 5.71 \\
\hline & No & $0 / 30$ & 0.00 & $0 / 30$ & 0.00 \\
\hline \multirow[t]{2}{*}{ JA57 } & Yes & $3 / 35$ & 8.57 & $3 / 35$ & 8.57 \\
\hline & No & $0 / 30$ & 0.00 & $0 / 30$ & 0.00 \\
\hline
\end{tabular}

The results suggested that chicks selected for fast growth, such as Cobb, are less dependent on endogenous nutrition, responding better when yolk assimilation and exogenous nutrition via diet are associated. However, the yolk sac is essential for growth initiation of light-strain birds (Hy-Line).

\section{REFERENCES}

Chamblee TN, Brake JD, Schultz CD, Thaxton JP. Yolk sac absorption and initiation of growth in broilers. Poultry Science 1992; 71:18111816.

Gonzales E, Leandro NSM, Varoli Jr JC, Takita TS, Loddi MM. O tempo de jejum do neonato e a restrição alimentar quantitativa influenciando a produtividade de frangos de corte na idade de abate. Revista Brasileira de Ciência Avícola 2000; (Supl 2):4.

Gonzales E, Kondo N, Saldanha ESPB, Loddi MM, Careghi C, Pizzolante CC, Decuypere E. Performance and physiological parameters of broiler chickens subjected to fasting on the neonatal period. Poultry Science 2003; 82:1250-1256.

Nitsan Z, Dunnington EA, Wiegel PB. Organ growth and digestive enzyme levels to fifteen days of age in lines of chickens differing in body weight. Poultry Science 1991; 70:2040-2048.

Noy Y, Sklan D. Yolk and exogenous feed utilization in the posthatch chick. Poultry Science 2001; 80:1490-1495.

Thaxton JP. Deutectomy and humoral immunity in neonatal broilers. Poultry Science 1984; 63 (Suppl 1):41.

SAEG - Sistemas de análises estatísticas [cd-rom]. Viçosa: Fundação Arthur Bernardes; 1999. 